\title{
Gamma Irradiation and $\mathrm{NaCl}$ Treatment on the Embryonic Callus of Rice (Oryza sativa L.) Cultivar Kuliyadichan and CO 43 for Salt Tolerance
}

\author{
R. Venkateshan ${ }^{1}$, S. Merina Prem Kumari ${ }^{1 *}$, M. Arumugam Pillai ${ }^{1}$, \\ S. Saravanan ${ }^{1}$ and A. Kavitha Pushpam ${ }^{2}$ \\ ${ }^{1}$ Department of Plant Breeding and Genetics, ${ }^{2}$ Department of Soil Science and Agricultural \\ Chemistry, Agricultural College and Research Institute, Killikulam, \\ Vallanad-628252, Tamil Nadu, India \\ *Corresponding author
}

\author{
A B S T R A C T
}

\begin{tabular}{|l|}
\hline K e y w o r d s \\
Rice, Embryonic \\
calli, Gamma \\
irradiation, $\mathrm{NaCl}$ \\
${\text { stress, } \mathrm{LD}_{50} \text { and }}_{\mathrm{LC}_{50}}$ \\
\hline Article Info \\
\hline $\begin{array}{l}\text { Accepted: } \\
10 \text { August } 2020 \\
\text { Available Online: } \\
10 \text { September } 2020\end{array}$ \\
\hline
\end{tabular}

\section{Keywords}

Rice, Embryonic calli, Gamm stress, $\mathrm{LD}_{50}$ and

\section{Article Info}

Accepted:

Available Online:

10 September 2020

\begin{abstract}
The present study investigated the effect of gamma irradiation and $\mathrm{NaCl}$ treatment on the embryonic calli of indica rice variety Kuliyadichan and CO43. Embryonic calli obtained from both the varieties were exposed to gamma irradiation $(0,20,30,40$ and $50 \mathrm{~Gy})$ and lethal dose $\mathrm{LD}_{50}$ based on calli survival and regeneration capacity was determined. The $\mathrm{LD}_{50}$ based on calli survival was deduced as $34.31 \mathrm{~Gy}$ and $31.01 \mathrm{~Gy}$ for Kuliyadichan and CO43 respectively. Similarly the $\mathrm{LD}_{50}$ based on regeneration capacity was deduced as 27.09 Gy and 24.01 Gy for variety Kuliyadichan and CO43. Furthermore, embryonic calli from both varieties were exposed to four different $\mathrm{NaCl}$ concentrations with electrical conductivity of $4,8,10$ and $12 \mathrm{dS} / \mathrm{m}$ and the lethal concentration $\mathrm{LC}_{50}$ based on calli survival and regeneration capacity was determined. The lethal concentration $\mathrm{LC}_{50}$ based on calli survival was fixed as $11.01 \mathrm{dS} / \mathrm{m}$ for Kuliyadichan and $10.24 \mathrm{dS} / \mathrm{m}$ for CO43. Similarly, the $\mathrm{LC}_{50}$ based on regeneration was fixed as $10.6 \mathrm{dS} / \mathrm{m}$ for variety Kuliyadichan and $9.19 \mathrm{dS} / \mathrm{m}$ for variety CO43. Based on overall consideration, the variety CO43 showed more sensitivity to gamma irradiation and $\mathrm{NaCl}$ stress than the variety Kuliyadichan.
\end{abstract}

\section{Introduction}

Rice (Oryza sativa $\mathrm{L}$.) is an important staple food for more than half of the world's population. It serves $20 \%$ of the calories to the human diet. World human population is increasing day by day and it is expected to be around 9-10 billion by 2050.Global consumption of rice has increased from 437.12 metric tons in 2008 to 495.5 metric tons in 2019 (Statista, 2020) and was projected to reach 852 metric tons by the year 2035 (Khush and Gurdev, 2013). But the agricultural production is dwindling year by year due to climate change, rainfall variability, and other abiotic stresses. Among the abiotic factors, salinity is a major threat that reduces the growth and development of plants. It is estimated that $32 \%$ of the irrigated lands and $20 \%$ of the total cultivated agricultural lands are affected by high salinity. Irrigation with saline water, high 
surface evaporation and poor cultural practices increase the rate of salinization by $10 \%$ annually and estimated to be increased up to $50 \%$ by 2050 (Jamil et al., 2011).

There are two ways to manage the salinity stress: 1) to change the environment that adopts for normal growth of plants and 2) to change the genetic architecture of the crop that adopts to salinity tolerance. The first method is a tedious and time-consuming process and requires a lot of soil amelioration process. The second approach i.e., breeding crops with in-built salinity tolerance is the most promising, socially accepted approach and requires less resource consumption. In light of the situation, crop genetic improvement in the agronomically important crops that are tolerant or resistant to salinity is important (Reddy et al., 2017).

Induced mutation is one of the ways to create genetic variability in plants. There are three ways to induce mutation viz., T-DNA insertion, using physical mutagens such as gamma rays, fast neutrons and electron beam and chemical mutagens such as MNU, EMS, and $\mathrm{NaN}_{2}$ (Serrat et al., 2014). Among these, physical and chemical mutagens are most commonly used (Penna et al., 2012). Once the plants have been treated with mutagens, the mutants are to be screened for any improvement in traits. Screening through conventional breeding requires more time and a large population to identify a desired mutant (Schaart et al., 2015). In such scenario, tissue culture techniques could be more advantageous than conventional breeding. The culture media could be modified by adding selection agents and the desirable mutants could be screened in a short period and in controlled conditions (Bado et al., 2015). The combined use of in vitro culture methods such as anther culture, somatic embryogenesis, protoplast fusion, and induced mutations can help to overcome some limitations in both seeds and vegetatively propagated crops (Maluszynki et al., 1995).

In vitro mutagenesis and somoclonal variations can help to improve agronomic traits like salinity and drought tolerance in different crop plants (Arzani and Ahmad, 2008). The present experiment was conducted to study the effect of gamma rays and $\mathrm{NaCl}$ salt on rice callus.

\section{Materials and Methods}

Seeds of rice cultivars viz., Kuliyadichan and CO 43 were selected because of the high callus induction frequency and regeneration frequency (Amaravel, 2019). Embryogenic calli generated from these seeds were used as experimental materials.

\section{Callus induction}

Selected healthy, fully matured seeds from each variety were dehusked by removing the lemma and pale a using sand paper and taken in a sterile centrifuge tube. The seeds were surface sterilized by immersing in $70 \%$ ethanol for $1 \mathrm{~min}$ followed by $50 \%$ commercial bleach $(\sim 5 \% \mathrm{NaOCl})$ for $10 \mathrm{~min}$ with shaking at $120 \mathrm{rpm}$. The seeds were rinsed with sterile deionised water (3 to 5 times) and dried for 5 min by placing on a sterilized tissue paper. Sterilized seeds were inoculated in callus induction medium (CIM) comprising of MS media (Murashige and Skoog, 1962) supplemented with $2.0 \mathrm{mg} / \mathrm{l}$ of 2, 4-dichlorophenoxyacetic acid (2, 4 -D) $0.5 \mathrm{mg} / \mathrm{l}$ of kinetin and $30 \mathrm{~g} / \mathrm{l}$ of sucrose as described by Amaravel (2019). The $\mathrm{pH}$ of the media was adjusted to 5.6-5.8 before adding Clerigel (Himedia, India) $3 \mathrm{~g} / \mathrm{l}$ as a gelling agent. The medium was sterilized by autoclaving at $15 \mathrm{psi}$ for $15 \mathrm{~min}$. The cultured plates were placed in the dark at a temperature of $27 \pm 2^{\circ} \mathrm{C}$ for three weeks for callus induction. The callus induction 
percentage of each variety was observed at the time of initiation

Callus induction percentage $=$ Number of seeds that produced callus $\times 100$

Total seeds cultured

After three weeks, induced calli from seeds were irradiated with gamma rays and were used to establish tolerance to salinity.

Mutagenesis of callus by gamma irradiation

Determination of sensitivity and growth response of irradiated callus

Healthy embryonic calli of the three rice cultivars were irradiated with gamma rays (Gamma chamber 5000, Indian Institute of Horticultural Research, Bangalore) with three replications and 12 calli per replication. Post irradiation, the calli were divided into 3-4 mm diameter tissues using a sterile scalpel. Up to 150 calli were transferred into freshly prepared CIM (Murashige and Skoog, 1962) and subcultured two times for every 13 days to eliminate the radiolysis hazards. The proliferating calli were observed by the cream color and the increase in mass and any browning due to phenolic exudation were considered irresponsive. After one month, the survival and weight of the callus were observed and recorded.

Relative differentiation rate $(\mathrm{RDR} \%)=\underline{\mathrm{N} 0 \text { of survived calli in treatment }} \times 100$ No of survived calli in control

Relative growth percentage $=\left(\mathrm{W}_{\mathrm{n}}-\mathrm{W}_{0} / \mathrm{W}_{0}\right) \mathrm{X}$ 100 ,

where $\mathrm{W}_{\mathrm{n}}$ is the weight of the callus at the end of the experiment

$\mathrm{W}_{0}$ is the weight of the callus at the start of the experiment.

\section{Effect of gamma radiation on regeneration percentage}

After two subcultures, some of the survived irradiated calli were transferred to regeneration media comprising of MS media supplemented with BAP $3 \mathrm{mg} / \mathrm{l}$, NAA 1.0 $\mathrm{mg} / \mathrm{l}$, maltose $30 \mathrm{~g} / \mathrm{l}$ and clerigel $3 \mathrm{~g} / \mathrm{l}$ (Amaravel, 2019). The cultures were maintained at $27 \pm 2^{\circ} \mathrm{C}$ with a $16 / 8 \mathrm{hr}$ light and dark period for 3-4 weeks. The regeneration response of each variety at different doses was recorded.

The regeneration frequency was calculated based on the formula,

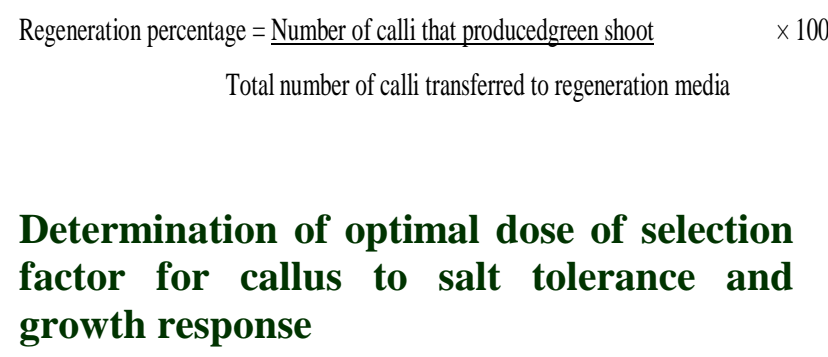

Determination of optimal dose of selection factor for callus to salt tolerance and growth response

Non irradiated calli were grown in CIM with electrical conductivity of $4,8,10$, and $12 \mathrm{dS} / \mathrm{m}$ salt stress to study the effect of salinity on callus formation and to determine the optimal dose for selection factor. The cultures were maintained at $27 \pm 2{ }^{\circ} \mathrm{C}$ in dark for a period of 3-4 weeks. The treatments consisted of three replicates and each replicate consisting of 12 calli per rice variety. After three weeks, survival of calli and relative growth rate were observed.

\section{Effect of $\mathrm{NaCl}$ treatment on regeneration percentage}

After 4 weeks, some of the $\mathrm{NaCl}$ stress survived calli were transferred to regeneration media comprising of MS media supplemented with BAP $3 \mathrm{mg} / \mathrm{l}$, NAA $1.0 \mathrm{mg} / \mathrm{l}$, maltose 30g/l and clerigel 3g/l (Amaravel, 2019) with 
electrical conductivity of $4,8,10$ and $12 \mathrm{dS} / \mathrm{m}$. The cultures were maintained at 27 $\pm 2^{\circ} \mathrm{C}$ with a $16 / 8 \mathrm{hr}$ light and dark period for 3-4 weeks. The regeneration response of each variety at different doses was recorded.

\section{Statistical analysis}

Radio sensitivity assay of irradiated callus and salt sensitivity of non-irradiated callus for each variety based on relative differentiation rate was analysed by linear regression in Completely Randomized Design (CRD). The $\mathrm{LD}_{50}$ and $\mathrm{LC}_{50}$ was fixed by using the Curve Expert1.4 program. The in vitro growth response data were analysed by analysis of variance (ANOVA) and mean comparison by Tukey HSD at $0.05 \%$ significance by SPSS software version 16.0.

\section{Results and Discussion}

\section{Callus induction percentage}

In rice tissue culture, callus induction depends upon number of factors such as, genotype of the mother plant, composition of the basal salts and organic compounds, type of explants, and plant growth regulators used in callus induction (Khaleda and Al-Forkan, 2006).Even within the indica rice varieties, significant variations in in vitro culture of different genotypes were observed. The callus induction media for the rice cultivars used in this study was standardized previously (Amaravel, 2019).

The best combination for obtaining maximum callus was observed as MS medium, (Murashige and Skoog, 1962) supplemented with 2, $4-\mathrm{D} 2.0 \mathrm{mg} / \mathrm{l}$, kinetin $0.5 \mathrm{mg} / \mathrm{l}$ and sucrose $30 \mathrm{~g} / \mathrm{l}$. Among the varieties tested, maximum callus induction was observed in Kuliyadichan $(85.6 \%)$ followed by $\mathrm{CO} 43$ (82\%).
Mutagenesis of rice calli by gamma irradiation

\section{Determination of radiation sensitivity of the irradiated callus}

Fresh actively proliferating embryonic calli showed sensitivity to gamma irradiation. The survival rate of the embryonic calli decreased with the increase in irradiation dose and the different rice cultivars showed different percentage of survival rate (Fig. 1A-D). The relative differentiation rate of irradiated callus based on survival of calli and the ability to produce regeneration was calculated (Table 1 and 2). This suggests that the genotype of the cultivar is important in determining the radiation stress survival rate. Furthermore, it emphasizes the need for fixation of optimal radiation dose for every cultivar to get maximum heritable mutations with limited lethality. The irradiation causes the production of free radicles such as $\mathrm{H}^{+}$and $\mathrm{OH}^{-}$due to the interaction with the water molecules present in the treated cells which leads to plant cell death (Taheri et al., 2014) Also a reduction of survival percent was reported in rice (Abdelnour et al., 2020) (Yunita et al., 2020), in sugarcane (Nikam et al., 2015) (Patade et al., 2008) and in Citrus recticulata $\mathrm{cv}$. Limau Madu (Agisimanto et al., 2016).

In any mutation-induced program, the determination of the radiosensitivity is essential for identifying the suitable dose for inducing mutation in particular cultivars. Radiosensitivity of irradiated embryonic callus $\left(\mathrm{LD}_{50}\right)$ can be found from the relative differentiation rate based on callus survival percentage and the regeneration rate.

The linear regression equation for two different varieties based on the percentage of survival and regeneration is shown in Figure 2. The lethal doses $\left(\mathrm{LD}_{50}\right)$ based on callus 
survival percentage of the two cultivars viz., Kuliyadichan, and CO 43 was fixed as 34.81 Gy, and 31.01 Gy respectively. Similarly, the lethal dose $\left(\mathrm{LD}_{50}\right)$ based on regeneration percentage was fixed as 27.09 Gy for variety Kuliyadichan and 24.21 Gy for variety CO 43.

The $\mathrm{LD}_{50}$ of the irradiated embryonic callus of upland rice variety Situpatenggang and Batutegi was 24.68 Gy and 22.15 Gy (Yunita et al., 2020). The lethal dose of irradiated embryonic calli was 200Gy and 60 Gy based on survival percentage and plant regeneration percentage respectively in rice variety $\mathrm{CR}$ 5272 (Abdelnour et al., 2020). Agisimanto et al., (2016) determined that the mean lethal irradiation dose $\left(\mathrm{LD}_{50}\right)$ of Citrus reticulate $c v$. Limau Madu was 30Gy for the callus induction. Saif et al., (2001) reported that the $\mathrm{LD}_{50}$ for the sugarcane variety $\mathrm{CP}-43 / 33$ and potato cv Cardinal was 20Gy. Thereby each crop variety with varying response to gamma radiation has been documented.

Table.1 Effect of gamma irradiation on relative differentiation rate of embryonic calli of Kuliyadichan and $\mathrm{CO} 43$

\begin{tabular}{|c|c|c|c|c|c|}
\hline \multirow{2}{*}{ S.No } & $\begin{array}{c}\text { Gamma } \\
\text { radiation dose } \\
\end{array}$ & \multicolumn{2}{|c|}{ Kuliyadichan } & \multicolumn{2}{|c|}{ CO 43 } \\
\cline { 3 - 6 } & $\begin{array}{c}\text { No.of survived } \\
\text { calli }\end{array}$ & RDR $(\%)$ & $\begin{array}{c}\text { No. of survived } \\
\text { calli }\end{array}$ & RDR (\%) \\
\hline $\mathbf{1}$ & 0 (control) & 143 & 100 & 145 & 100 \\
\hline $\mathbf{2}$ & 20 & 118 & 82.51 & 120 & 82.75 \\
\hline $\mathbf{3}$ & 30 & 63 & 44.05 & 65 & 44.82 \\
\hline $\mathbf{4}$ & 40 & 60 & 41.25 & 45 & 31.03 \\
\hline $\mathbf{5}$ & 50 & 46 & 32.16 & 26 & 17.93 \\
\hline
\end{tabular}

Table.2 Effect of gamma irradiation on the regeneration of rice varieties Kuliyadichan and $\mathrm{CO} 43$

\begin{tabular}{|c|c|c|c|c|c|c|c|}
\hline Variety & $\begin{array}{c}\text { Dosage of } \\
\text { gamma } \\
\text { irradiation } \\
(\mathbf{G y})\end{array}$ & $\begin{array}{l}\text { No. of calli } \\
\text { inoculated }\end{array}$ & $\begin{array}{c}\text { No. of } \\
\text { calli that } \\
\text { turned } \\
\text { green }\end{array}$ & $\begin{array}{l}\text { No. of calli } \\
\text { regenerated }\end{array}$ & $\begin{array}{c}\text { Regeneration } \\
\text { percentage } \\
(\%)\end{array}$ & $\begin{array}{c}\text { Relative } \\
\text { differentiation } \\
\text { rate }(\%)\end{array}$ & $\begin{array}{l}\text { No. of } \\
\text { albino } \\
\text { plants }\end{array}$ \\
\hline \multirow{5}{*}{ 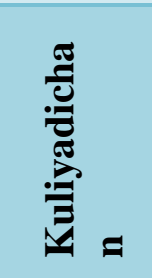 } & 0 & 35 & 30 & 24 & $68.57 \%$ & 100 & _- \\
\hline & 20 & 35 & 30 & 16 & $45.7 \%$ & 66.66 & _- \\
\hline & 30 & 35 & 21 & 10 & $28.57 \%$ & 41.66 & 1 \\
\hline & 40 & 35 & 10 & 5 & $14.2 \%$ & 20.83 & 1 \\
\hline & 50 & 35 & 8 & 3 & $8.5 \%$ & 12.5 & 1 \\
\hline \multirow{5}{*}{$\stackrel{?}{8}$} & 0 & 35 & 28 & 20 & $57.14 \%$ & 100 & - \\
\hline & 20 & 35 & 18 & 13 & $37.14 \%$ & 65 & - \\
\hline & 30 & 35 & 12 & 7 & $20.1 \%$ & 35 & 1 \\
\hline & 40 & 35 & 3 & 2 & $5.7 \%$ & 10 & 2 \\
\hline & 50 & 35 & 0 & 0 & 0 & 0 & - \\
\hline
\end{tabular}


Table.3 Relative growth rate of rice varieties Kuliyadichan, and CO 43 subject to gamma irradiation

\begin{tabular}{|c|c|c|}
\hline Gamma & \multicolumn{2}{|c|}{ Fresh weight of callus $(\mathbf{g})$} \\
\hline irradiation $(\mathbf{G y})$ & Kuliyadichan & CO 43 \\
\hline & & \\
\hline $\mathbf{0}$ & $2.08_{\mathrm{a}} \pm 0.03$ & $1.71_{\mathrm{a}} \pm 0.03$ \\
\hline $\mathbf{2 0}$ & $1.87_{\mathrm{a}} \pm 0.09$ & $1.30_{\mathrm{b}} \pm 0.09$ \\
\hline $\mathbf{3 0}$ & $1.28_{\mathrm{b}} \pm 0.04$ & $0.81_{\mathrm{c}} \pm 0.10$ \\
\hline $\mathbf{4 0}$ & $0.94_{\mathrm{c}} \pm 0.07$ & $0.60_{\mathrm{cd}} \pm 0.06$ \\
\hline $\mathbf{5 0}$ & $0.70_{\mathrm{d}} \pm 0.07$ & $0.27_{\mathrm{d}} \pm 0.04$ \\
\hline CD at $\mathbf{0 . 0 5 \%}$ & 0.217 & 0.253 \\
\hline CD at $\mathbf{0 . 0 1 \%}$ & 0.308 & 0.361 \\
\hline
\end{tabular}

Data represent the mean of the replicates \pm S.E values. Mean followed by the same letter in the same column does not differ according to post hoc test Tukey HSD analysis at the level of 5\% significance

Table.4 Effect of different salt stress on relative differentiation rate of embryonic calli of Kuliyadichan and $\mathrm{CO} 43$

\begin{tabular}{|c|c|c|c|c|c|}
\hline \multirow{2}{*}{ S.No } & \multirow{2}{*}{$\begin{array}{c}\text { NaCl Stress } \\
\text { media (dS/m) }\end{array}$} & \multicolumn{2}{|c|}{ Kuliyadichan } & \multicolumn{2}{|c|}{ CO 43 } \\
\cline { 3 - 6 } & $\begin{array}{c}\text { No. of survived } \\
\text { calli }\end{array}$ & RDR $(\%)$ & $\begin{array}{c}\text { No. of survived } \\
\text { calli }\end{array}$ & RDR (\%) \\
\hline $\mathbf{1}$ & 4 (control) & 34 & 100 & 35 & 100 \\
\hline $\mathbf{2}$ & 8 & 28 & 82.35 & 29 & 82.85 \\
\hline $\mathbf{3}$ & 10 & 21 & 61.76 & 18 & 51.42 \\
\hline $\mathbf{4}$ & 12 & 12 & 35.2 & 10 & 28.57 \\
\hline
\end{tabular}

Table.5 Effect of $\mathrm{NaCl}$ on the regeneration of rice varieties Kuliyadichan and $\mathrm{CO} 43$

\begin{tabular}{|c|c|c|c|c|c|}
\hline Variety & $\begin{array}{l}\text { NaCl Stress } \\
\text { media }(d S / m)\end{array}$ & $\begin{array}{l}\text { No.ofcalli } \\
\text { Inoculated }\end{array}$ & $\begin{array}{l}\text { No. of calli } \\
\text { regenerated }\end{array}$ & $\begin{array}{c}\text { Regeneration } \\
\text { percentage (\%) }\end{array}$ & $\begin{array}{c}\text { Relative } \\
\text { differentiation } \\
\text { rate }(\%)\end{array}$ \\
\hline \multirow{4}{*}{ 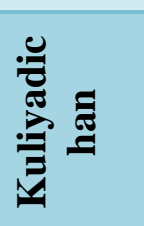 } & 4 (control) & 10 & 8 & 80 & 100 \\
\hline & 8 & 10 & 7 & 70 & 87.5 \\
\hline & 10 & 10 & 5 & 50 & 62.5 \\
\hline & 12 & 10 & 2 & 20 & 25 \\
\hline \multirow{4}{*}{$\stackrel{?}{\mathscr{\theta}}$} & 4 (control) & 10 & 6 & 60 & 100 \\
\hline & 8 & 10 & 5 & 50 & 83.33 \\
\hline & 10 & 10 & 3 & 30 & 50 \\
\hline & 12 & 10 & 0 & 0 & 0 \\
\hline
\end{tabular}


Table.6 Effect of $\mathrm{NaCl}$ on the relative growth rate of calli in rice varieties Kuliyadichan and CO 43

\begin{tabular}{|c|c|c|c|}
\hline S.No & NaCl stress media & \multicolumn{2}{|c|}{ Relative growth rate (RGR) } \\
\cline { 3 - 4 } & $(\mathbf{d S} / \mathbf{m})$ & Kuliyadichan & CO 43 \\
\hline $\mathbf{1}$ & 4 (control) & $2.01_{\mathrm{a}} \pm 0.03$ & $1.70_{\mathrm{a}} \pm 0.07$ \\
\hline $\mathbf{2}$ & 8 & $1.63_{\mathrm{b}} \pm 0.03$ & $1.45_{\mathrm{a}} \pm 0.08$ \\
\hline $\mathbf{3}$ & 10 & $1.28_{\mathrm{c}} \pm 0.05$ & $0.81_{\mathrm{b}} \pm 0.06$ \\
\hline $\mathbf{4}$ & 12 & $0.76_{\mathrm{d}} \pm 0.15$ & $0.50_{\mathrm{b}} \pm 0.11$ \\
\hline & $\mathrm{C}$ D at $0.05 \%$ & 0.120 & 0.132 \\
\hline & $\mathrm{C}$ D at $0.01 \%$ & 0.175 & 0.201 \\
\hline
\end{tabular}

Data represent the mean of the replicates \pm S.E values. Mean followed by the same letter in the same column does not differ according to post hoc test Tukey HSD analysis at the level of 5\% significance

Fig.1 Effect of gamma irradiation on the embryonic calli of rice. (I)Embryonic calli formation at $10^{\text {th }}$ day after inoculation of seed (A) Kuliyadichan and (B) CO 43.(II)30Gy gamma irradiated callus after 26 days (C) Kuliyadichan and (D) CO 43.(III)Regeneration of 30 Gy gamma irradiated callus after 26 days (E) Kuliyadichan and (F) CO 43

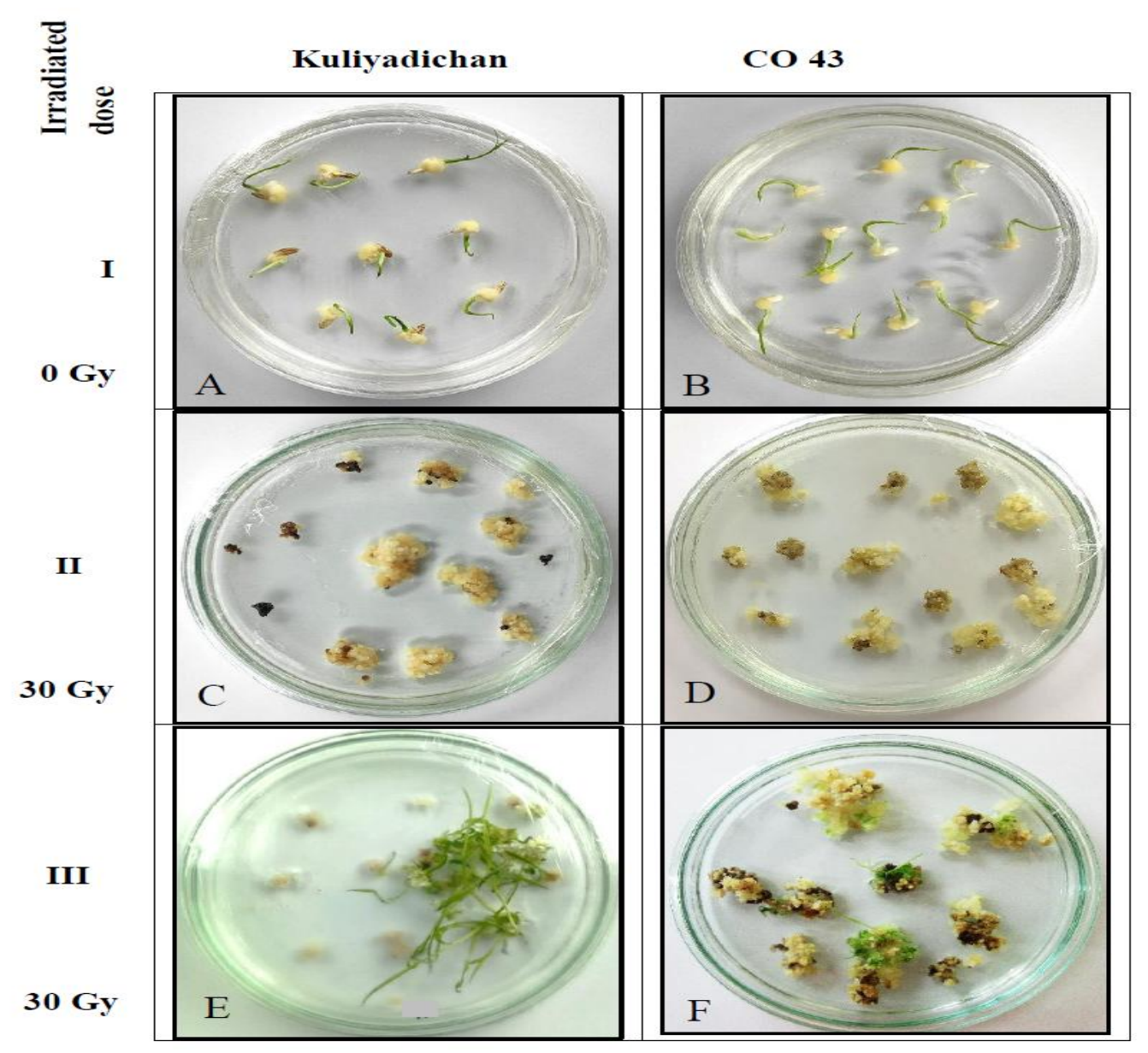


Fig.2 Radiosensitivity assay of irradiated embryonic calli based on relative differentiation rate from survival percentage of callus (A) Kuliyadichan and (B) $\mathrm{CO} 43$, and from regeneration percentage (C) Kuliyadichan and (D) CO 43

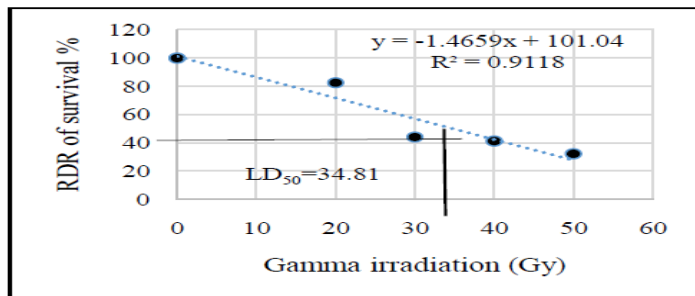

(A)

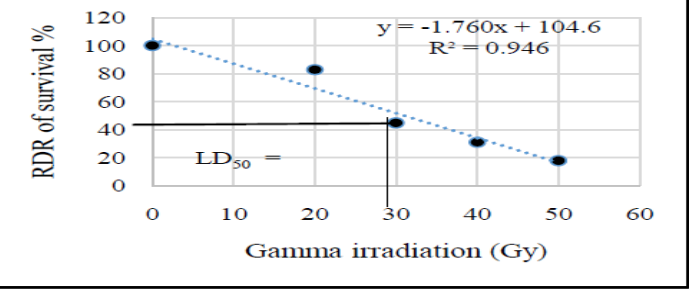

(B)

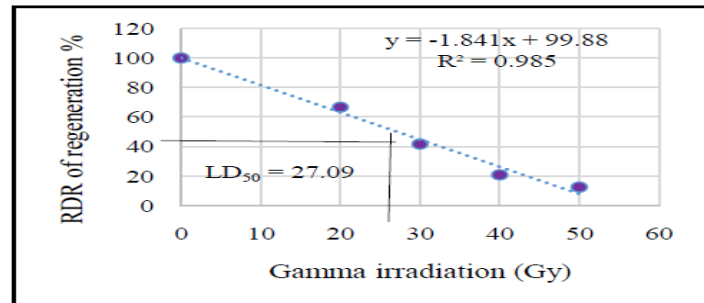

(C)

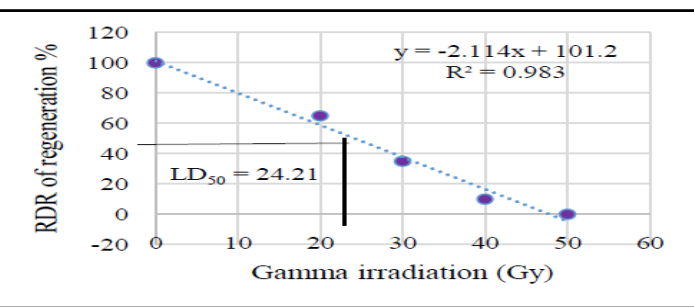

(D)

Fig.3 Effect of $\mathrm{NaCl}$ on the embryonic calli of rice.(I)Morphology of embryonic calli after 3 weeks in non-stress (control) medium. (A) Kuliyadichan and (B) CO 43 and(II) in $10 \mathrm{dS} / \mathrm{m} \mathrm{Nacl}$ stress medium (C) Kuliyadichan and (D) CO 43.(III) Regeneration of embryonic calli in $10 \mathrm{dS} / \mathrm{m}$ $\mathrm{NaCl}$ stress media after 3 weeks (E) Kuliyadichan and (F) CO 43

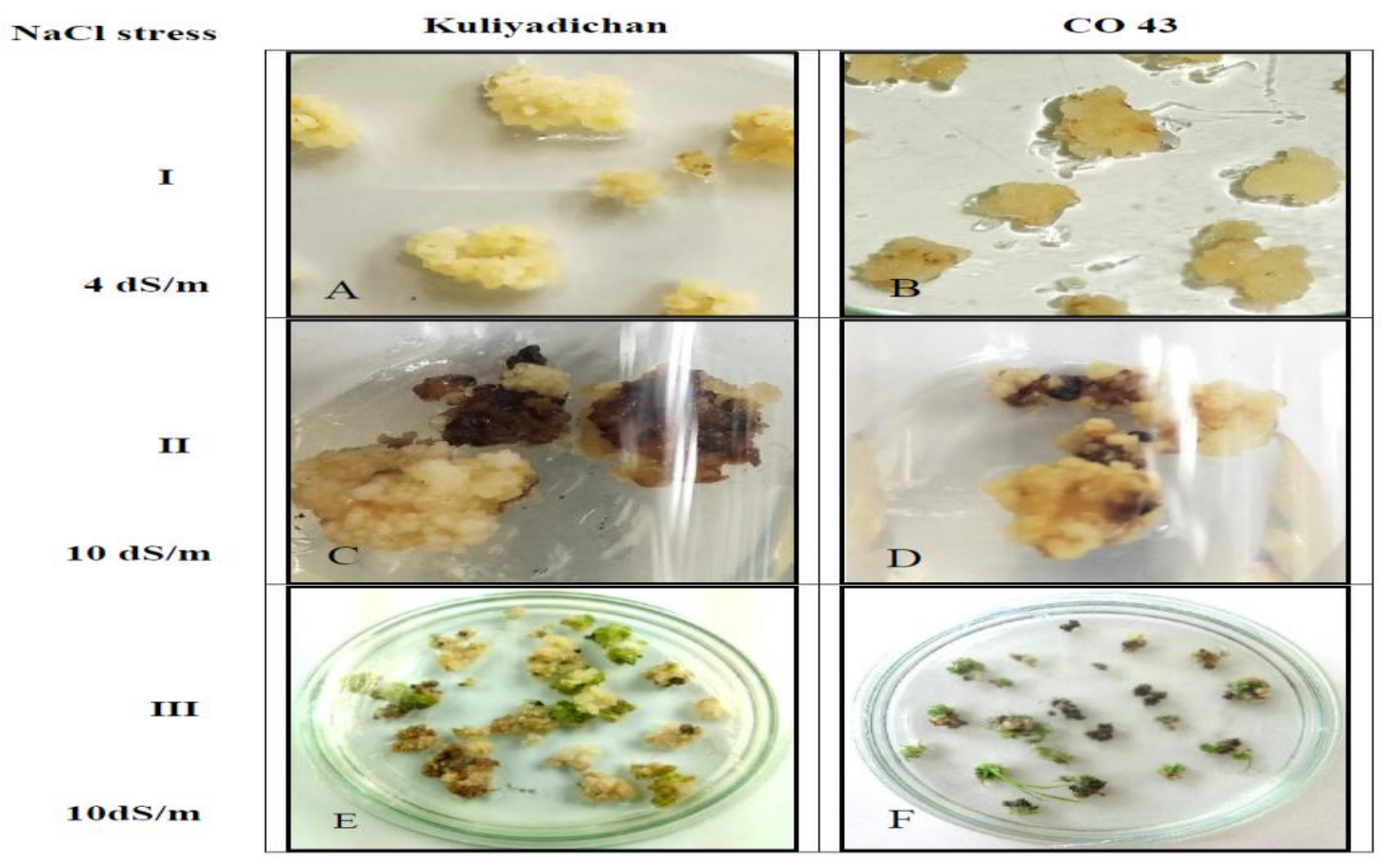


Fig.4 Salt sensitivity assay for embryonic calli based on relative differentiation rate from survival percentage of callus (A) Kuliyadichan and (B) CO 43, and from regeneration percentage (C) Kuliyadichan and (D) CO 43

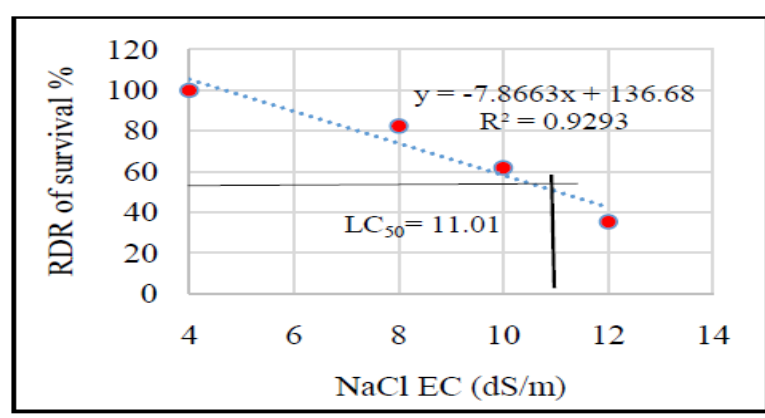

(A)

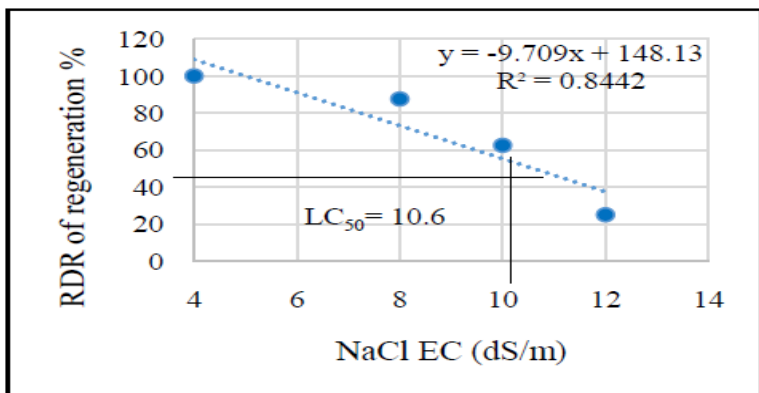

(C)

\section{Invitro growth response of irradiated callus}

A gradual decrease in the fresh weight of callus was observed in the irradiated calli when compared to control. In this study, the relative growth rate of callus showed a decreasing trend as the irradiation dose increased from 0 to $50 \mathrm{~Gy}$, and a significant difference was observed among each genotypes. In the two rice cultivars, the RGR was higher in control and lower in calli irradiated with 50 Gy dose (Table 3).

In this case, the radiation has a strong influence on callus growth and development. Physiologically gamma rays affect the cell wall and cell membrane and may cause changes in callus tissues. The callus growth inhibition at higher doses may be attributed to the cell cycle arrest at the G2/M phase during the somatic cell division or due to damage in the entire genome (Preuss and Britt, 2003)

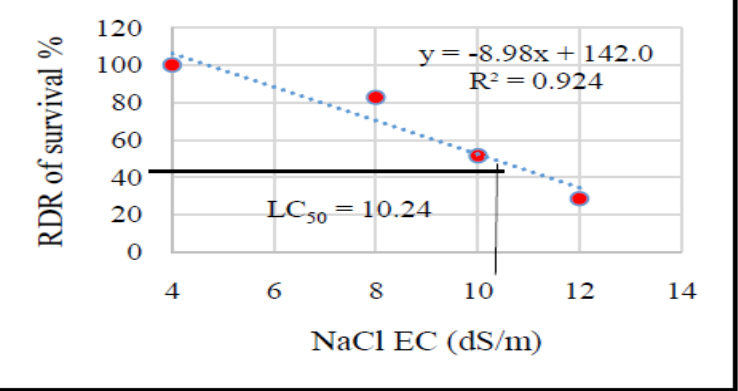

(B)

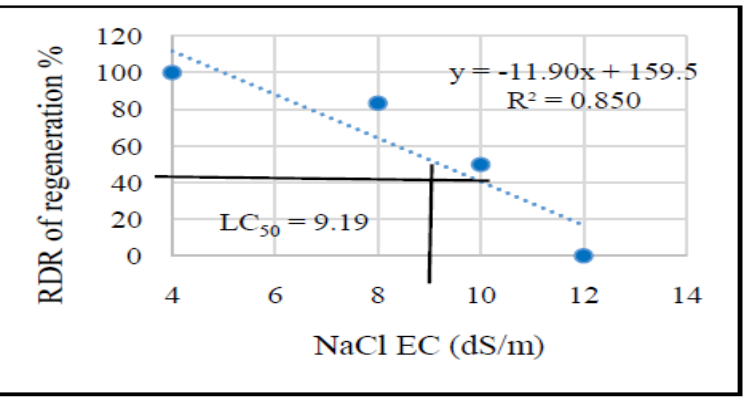

(D)

The callus proliferation was reported to be affected in sugarcane (Nikam et al., 2015) (Patade et al., 2008), Gerbera (Hasbullah et al., 2012) and Phaseolus vulgaris (Bajaj et al., 1970). According to (Nikam et al., 2015) a $50 \%$ reduction of callus growth was observed when exposed to low dose gamma irradiation of 10 and 20 Gy (Khalil et al., 2015) observed a significant reduction of callus proliferation in the irradiated callus of Stevia rebaudiana when compared to the untreated callus culture.

\section{Regeneration response of irradiated calli}

The regeneration percentage was calculated based on the emergence of green shoots with shoot length more than $3 \mathrm{~cm}$. The regeneration percentage of the plants decreased with the increasing radiation dose. Among the two varieties, the highest regeneration percentage of $68.57 \%$ was observed in Kuliyadichan 
followed by $\mathrm{CO} 43$ with $57.14 \%$ in calli without gamma irradiation. Similar to the callus survival percentage, increasing the gamma irradiation dosage resulted in reduction of regeneration percentage. About $50 \%$ reduction of regeneration percentage was observed based on RDR at a dosages between 20-30Gy in the two experimentally taken cultivars (Fig. 1E-F).

Moustafa et al., (1989) observed decreased plant regeneration capacity with the increasing levels of radiation dosage and $50 \%$ inhibition was found at 25Gy. (Patade et al., 2008) also reported better regeneration potentials of non-irradiated embryonic callus of sugarcane than the irradiated callus. Saif $e t$ al., (2001) obtained only 4-5\% regeneration frequency when sugarcane and potato calli were irradiated with 60Gy dose.

In addition, abnormality in plant shoot growth like weak culm and albino were observed in the calli irradiated above 30Gy radiation. (Hasbullah et al., 2012) observed in the callus tissues, the loss of capacity to differentiate and form shoots when irradiated with a higher dose of gamma irradiation.

The invitro regenerated shoots were transferred to half MS media for the development of roots. The irradiated calli took 30-40 days for sufficient root growth before the hardening process. Some of the plants of around 1-2\% showed poor or no root formation. After the complete plant establishment, they were maintained in liquid half MS medium without hormones for one week and then transferred to the greenhouse for hardening

\section{Determination of optimal dose of selection factor for callus to salt tolerance}

Increasing the salt stress in media decreases the survival and relative growth rate of embryonic calli. The relative differentiation rate of embryonic calli based on survival percentage of callus and regeneration capacity in different salt stress media is shown in (Table 4 and 5). Two rice cultivars Kuliyadichan and CO 43 showed different sensitivity to $\mathrm{NaCl}$. The color of the calli turned to brown or black when exposed to increasing concentration of $\mathrm{NaCl}$ in the culture media (Fig. 3A-D).

The linear regression equation for two different varieties based on the relative differentiation rate of survived calli and regeneration is shown in the Figure 4. The optimal dose of selection factor $\left(\mathrm{LC}_{50}\right)$ for the variety Kuliyadichan and $\mathrm{CO} 43$ was fixed as 11.01 EC and 10.24 EC respectively. Similarly, the $\mathrm{LC}_{50}$ based on regeneration percentage was fixed as 10.6 EC for variety Kuliyadichan and 9.19 EC for variety CO 43.

Increasing the $\mathrm{NaCl}$ level in the medium and the consequent nature of ionic osmoticum accounts for the decrease in the percentage of survival of callus. Callus browning and necrosis increased when $\mathrm{NaCl}$ concentration was elevated.

This could be due to the genotype effect and low osmotic potential of cells that create differences in the survival percentage within the genotypes (Haque et al., 2017). Rattana et al., (2015) reported that the calli showed a decrease in the survival percentage when exposed to increasing $\mathrm{NaCl}$ concentration in culture media.

The callus browning is the indicator of tissue damage (Wu et al., 2005) and the abiotic and biotic stress induce the synthesis of phenolic compounds that may result in callus browning (Koc et al., 2009). The influence of salinity on callus viability is greatly influenced by genotype (Haque et al., 2017). 
In vitro callus growth response under $\mathrm{NaCl}$ stress

The addition of $\mathrm{NaCl}$ in the culture media caused a decrease in callus growth in the two genotypes and a significant difference was noticed in variety Kuliyadichan. Table 6 shows the effect of increasing salt stress on the relative growth rate of callus. In each variety, the relative growth rate of control was higher than the calli exposed to increasing concentrations of $\mathrm{NaCl}$ stress with electrical conductivity of 4 (control),8, 10 and $12 \mathrm{dS} / \mathrm{m}$.

In the present study, the RGR was decreased with the increasing $\mathrm{NaCl}$ concentration. (Haque et al., 2017) reported this phenomena of reduced relative growth rate in $\mathrm{NaCl}$ stress might happen due to the reduction of water availability and loss of turgor pressure in the cells. A similar result was reported by (Sankepally et al., 2016) and (Lutts et al., 1998) in rice and (Patade et al., 2008) in sugarcane.(Sankepally et al., 2016) observed reduction of callus growth in six cultivars of rice when exposed to different $\mathrm{NaCl}$ concentrations of 50,100,150,200, 225, and $250 \mathrm{mM}$ in culture media. Reddy and Vaidyanath (1986) observed decline in the fresh weight of callus from $212 \mathrm{mg}$ in control condition to $120 \mathrm{mg}$ in $2 \% \mathrm{NaCl}$ stress condition in culture media. Shankhdhar et al., (2000) observed decrease in the fresh weight of callus with increasing salt concentration and reported that the reduction of water availability might be a reason for the decrease in fresh weight with an increase in salt concentration.

Invitro regeneration response under $\mathrm{NaCl}$ stress

The inherent capacity of the rice calli to regenerate in salt-stress conditioned tissue culture medium was evaluated on the basis of regeneration potential. The regeneration percentage of calli was decreased in linear fashion with increase in salt stress (Table 5). Normal plant regeneration was observed in media without $\mathrm{NaCl}$ (control), but increased $\mathrm{NaCl}$ concentration in the medium decreased the regeneration capacity in rice varieties Kuliyadichan and CO43 (Fig.3E-F). Regeneration percentage of rice variety Kuliyadichan was $80 \%$ at $4 \mathrm{dS} / \mathrm{m}$ (control) but further decreased to $50 \%$ in $10 \mathrm{dS} / \mathrm{m}$ of $\mathrm{NaCl}$ and to $20 \%$ in $12 \mathrm{dS} / \mathrm{m}$ of $\mathrm{NaCl}$. In the rice variety $\mathrm{CO} 43$, the plant regeneration on 4 $\mathrm{dS} / \mathrm{m}$ (control) was $60 \%$ which further decreased to $30 \%$ on $10 \mathrm{dS} / \mathrm{m}$ of $\mathrm{NaCl}$. No regeneration was found in medium with 12 $\mathrm{dS} / \mathrm{m} \mathrm{NaCl}$ stress. Similar result of decreased regeneration capacity of rice callus when exposed to increasing concentration of $\mathrm{NaCl}$ stress was reported elsewhere (Yunita et al., 2014) and (Shanthi et al., 2010). (Aditya and Backer, 2006) reported that the reduction of differentiation capability was due to presence of $\mathrm{NaCl}$ in the regeneration medium.

In conclusion the overall study on the effect of gamma irradiation and $\mathrm{NaCl}$ treatment on the embryonic calli survival, callus growth and regeneration of two rice varieties, Kuliyadichan and $\mathrm{CO} 43$ concluded that the variety $\mathrm{CO} 43$ was more radiosensitive and salt sensitive than the variety Kuliyadichan. The callus survival, callus growth and regeneration were profoundly affected by gamma irradiation and $\mathrm{NaCl}$ in both varieties with linear fashion of increasing dose and $\mathrm{NaCl}$ stress.

\section{References}

Abdelnour, E., Ana, Jason, P., Miguel, R., Walter, V., and Andres G. A. 2020. Use of gamma radiation to induce mutations in rice (Oryza sativa L.) and the selection of lines with tolerance to salinity and drought. In Vitro Cellular \& Developmental Biology-Plant. 56 (1): 88-97. 
Aditya T L, and B A Baker, 2006. Selection of salt tolerant somaclones from Indica rice through continuous in vitro and ex vitro sodium chloride stress. Indian J. Plant Physiol. 11: 349-357.

Agisimanto, Dita, Normah, M.N., Rusil, I., and Azhar Mohamad.2016. Gamma irradiation effect on embryonic callus growth of Citrus recticulata cv. Limau Madu. Sains Malaysiana. 45 (3):3229. 337.

Amaravel, 2019. Screening of rice (Oryza sativa., L) genotypes for developing salinity tolerance throught in vitro selection. M Sc Thesis, Department of Plant Breeding and Genetics, AC \& RI, Killikulam.

Arzani and Ahmad.2008. Improving salinity tolerance in crop plants: a biotechnological view. In Vitro Cellular and Developmental Biology-Plant. 44 (5): 373-383.

Bado et al (2015). Plant mutation breeding: current progress and future assessment. Plant breeding reviews. 39:23-88.

Bajaj, YPS, Saettler, A.W., Adams, M.W. 1970. Gamma irradiation studies on seeds, seedlings and callus tissue cultures of (Phaseolus vulgaris L). Radiation Botany 10 (2): 119-124.

Haque, Mozidul, Shahinul, I. and sreeramanan S. 2017. Effect of salt and heat pretreatment factors on efficient regeneration in barley (Hordeum vulgare L.,). 3 Biotech 7 (1): 63.

Hasbullah et al (2012). Irradiation effect on in vitro organogenesis, callus growth and plantlet development of Gerbera jamesonii. Horticultura Brasileira 30 (2): 252-257.

Jamil, Riaz, A.S., Ashraf, M. and Majid,R.F.2011. Gene expression profiling of plants under salt stress. Critical Reviews in Plant Sciences 30 (5): 435-458.

Khaleda, L. and Al-Forkan, M.2006. Genotypic variability in callus induction and plant regeneration through somatic embryogenesis of five deepwater rice
(Oryza sativa L) cultivars of Bangladesh. African Journal of Biotechnology 5 (16).

Khalil, L., Shahid, A., Nisar, A. and Roshan, Z.2015. Gamma radiation induced variation in growth characteristics and production of bioactive compounds during callogenesis in Stevia rebaudiana (Bert.). New Negatives in Plant Science $1: 1-5$.

Khush and Gurdev, S. 2013. Strategies for increasing the yield potential of cereals: case of rice as an example. Plant Breeding. 132(5): 433-436.

Koc, N.K., Bas, B., Koc, M. and Kusek, M. 2009. Investigation of in vitro selection for salt tolerant lines in sour orange (Citrus aurantium L). Biotechnology. 8(1):155-159.

Lutts, Stanley, Kinet, J.M. and Jules, B.1998. $\mathrm{NaCl}$ impact on somaclonal variation exhibited by tissue culture-derived fertile plants of rice (Oryza sativa $L$ ). Journal of Plant Physiology. 152(1):92103.

Maluszynski, Miroslaw, Beant, S. A. and Bjorn S.1995. Application of in vivo and in vitro mutation techniques for crop improvement. Euphytica. 85 (1-3):303315.

Moustafa, R.A.K., Duncan, D.R. and Widholm, J.M.1989. The effect of gamma radiation and $\mathrm{N}$-ethyl-N-nitrosourea on cultured maize callus growth and plant regeneration. Plant Cell, tissue and organ culture. 17 (2-3):121-132.

Murashige, Toshio and Folke Skoog. 1962. A revised medium for rapid growth and bio assays with tobacco tissue cultures. Physiologia plantarum. 15 (3):473-497.

Nikam et al (2015). Radiation-induced in vitro mutagenesis system for salt tolerance and other agronomic characters in sugarcane (Saccharum officinarum L). The Crop Journal.3 (1):46-56.

Patade, Vikas,Y., Suprasanna,P. and Bapat, V.A. 2008. Gamma irradiation of embryonic callus cultures and in vitro selection for salt tolerance in sugaracne 
(Saccharum officinarum L). Agricultural sciences in China. 7 (9):1147-1152.

Penna, Suprasanna, Sonawane, B.V. and Patade, V. Y. 2012. In vitro mutagenesis and selection in plant tissue cultures and their prospects for crop improvement. Bioremediation, Biodiversity, Bioavailability.6:6-14.

Preuss, S.B. and Britt, A.B. 2003. A DNAdamage induced cell cycle checkpoint in Arabidopsis. Genetics. 164(1):323-334.

Rattana, khwanduean, Sumontip and Bunnag. 2015. Differential salinity tolerance in calli and shoots of four rice cultivars. Asian Journal of Crop science. 7(1):48.

Reddy et al (2017). Salt tolerance in rice: focus on mechanism and approaches. Rice Science. 24(3):123-144.

Reddy and Vaidyanath, K. 1986. In vitro characterization of salt stress effect and the selection of salt tolerant plants in rice (Oryza sativa L). Theoretical and applied genetics. 71(5):757-760.

Saif, U.R., Asad,M.S., Zafar,Y. and Waheed, R.A. 2001. Use of radiation and in vitro techniques for development of salt tolerant mutants in sugarcane and potato.No.IAEA-TECDOC-1227.

Sankepally, S.S.R., Talluri, Arulmarianathan, J.P. and Singh, B. 2016. Callus induction and regeneration capabilities of indica rice cultivars to salt stress. J. Biomol. Res. Ther. 4(136).

Shanthi P, S Jebaraj and S Geetha, 2010. In vitro screening for salt tolerance in Rice (Oryza sativa). Electronic Journal of Plant Breeding. 1(4): 1208-1212.

Schaart et al (2015). Opportunities of New Breeding Techniques, Wageningen UR.

Serrat, Xavier, Roger, E., Nathalie, G., Luisa, M., Salvador, N. and Eric, L. 2014. EMS mutagenesis in mature seed derived rice calli as a new method for rapidly obtaining TILLING mutant population. Plant methods. 10(1):5.

Shankhdhar, D., Mani, S.C. and Pant, R.C.2000. In vitro selection for salt tolerance in rice. Biologia Plantarum. 43(3):477-480.

Statista.2020.http://www.statsita.com/statistics/ 255977/total-global-rice consumption/.

Wu, Jinglan, Denise, M.S. and John, L.G. 2005. The response of plasma membrane lipid composition in callus of the halophyte Spartina patens (Poaceae) to salinity stress. American Journal of Botany. 92(5):852-858.

Yunita, R., Iswari, S.D., Endang, G.L., Ragapadmi, P. and Suci, R. 2020. Formation of upland rice droughttolerant mutant by mutation induction and in vitro selection. Biodiversitos Journal of Biological Diversity.21 (4).

Yunita, R., N. Khumaida, D. Sopandie, and I. Mariska. 2014. Growth and regeneration of rice (Oryza sativa L.) callus in salt medium. Biosci. Res .11(1): 04-09.

\section{How to cite this article:}

Venkateshan, R., S. Merina Prem Kumari, M. Arumugam Pillai, S. Saravanan and Kavitha Pushpam, A. 2020. Gamma Irradiation and $\mathrm{NaCl}$ Treatment on the Embryonic Callus of Rice (Oryza sativa L.) Cultivar Kuliyadichan and CO 43 for Salt Tolerance. Int.J.Curr.Microbiol.App.Sci. 9(09): 1167-1179. doi: https://doi.org/10.20546/ijcmas.2020.909.145 